\title{
Supporting Mechanism and Technology of Roadway Overall along Goaf in Extremely Loose and Extra Thick Coal Seam
}

\author{
Renzhan Zhou \& Laiwang Jing \\ School of Civil Engineering and Architecture, Anhui University of Science and Technology, Huainan 232001, \\ P.R. China
}

\begin{abstract}
Taking machinery roadway, ventilation passage of Roadway 8203 of Guobei Mine in Huaibei Mining Group as the research background, applying basic theory of modern solid mechanics, interaction mechanism between metal bracket and bolt were studied in the condition of large loose circle, high ground pressure soft-rock roadway. Several key technologies of extremely loose and extra thick coal seam in supporting overall along goaf roadway were introduced in detailed. The functional mechanism of key technologies was not only analyzed in detail, but also on-site industrial tests were conducted. Good action effect of bolt and double resistant cloth was demonstrated in roadway of extremely loose coal seam, emphasizing the comprehensive effect of the composite support structure "metal bracket + bolt + double resistant cloth". On the one hand, the research results provided a significant effect, low-cost rock support technology; on the other hand, it also further improved the support theory of rock roadway. It has certain reference value for roadway supporting design in any case. It made the adjacent two mining areas into one and produced enormous economic benefits.
\end{abstract}

KEYWORD: the extremely loose and extra thick coal seam, Overall Roadway along Goaf, key technology, industrial test

\section{INTRODUCTION}

For a long time, the researches on the supporting technology of soft rock roadway with high ground pressure and loose coal seam have been more studied in the paper (Zhao Hongchao et al, 2011) (Liu Chaoru, 2011) (Wan Shiwen et al, 2011) (Li Jianmin et al, 2011) (Chen Baoyuan, 2010) (He Changhai et al, 2010) (Jing Laiwang et al, 2012) (Zhang Nong et al, 2009) (Wang Hezhi et al, 2008) (Zhao Yiming et al, 2008) (Wu Pengfei, 2010) (Zou Lei et al, 2010). Although some literatures which involved in supporting mechanism have made a lot of encouraging results (Jiang Yaodong et al, 2005) (Bai Jianbiao et al, 2008), there are still some aspects of mechanical mechanisms to be perfected. Some literatures (Sun Xiaoming et al, 2005) only use the numerical simulation for a certain degree of analysis. Because of the subjective factors in many cases, so it is difficult to accurately reflect the nature of the problem. However, in terms of supporting mechanism, most of the researches are partial to mechanism analysis of some single supporting condition, with combined supporting very little. Since the aspect of mechanical mechanism is a new mining and determine for supporting mechanisms and supporting effect, the research re- sults have practical significance to supporting design of high stress soft rock roadways in the current domestic and foreign.

\section{RESEARCH ON SUPPORTING MECHANISM}

\subsection{Supporting mechanism of anchor frame combination}

Mechanical mechanism of anchor frame support lies in the organic combination of the advantages of the U-shaped scaffolding and anchor support, and they improve each other in terms of carrying capacity. By means of the larger bite force, which formed by the overall constraint function of metal support to the surrounding rock among the broken rock blocks, the anchoring effect of bolt that anchored in the loose circle of surrounding rock has been greatly improved. On the one hand, bolt imposed outward force from short beam to the metal support, so that the anti-side pressure of metal support improved larger. And the rigidity and strength also improved significantly by aggrandizing the fulcrum of Ushaped scaffolding. On the other hand, the improvement of stiffness and bearing capacity of metal scaffold in turn increased the bite force between the 
broken rock, prompting increase of the anchoring force of bolt, eventually achieving the improvement purpose together between the bolt anchoring force and bearing capacity of the metal support. In addition, the effective range of the bolt increased shapely by means of large tray of metal support. The bearing capacity of bolt could be fully played, and ultimately got the supporting effect of $1+1>2$. The combined supporting structure of metal support and bolt was shown in Figure 1.

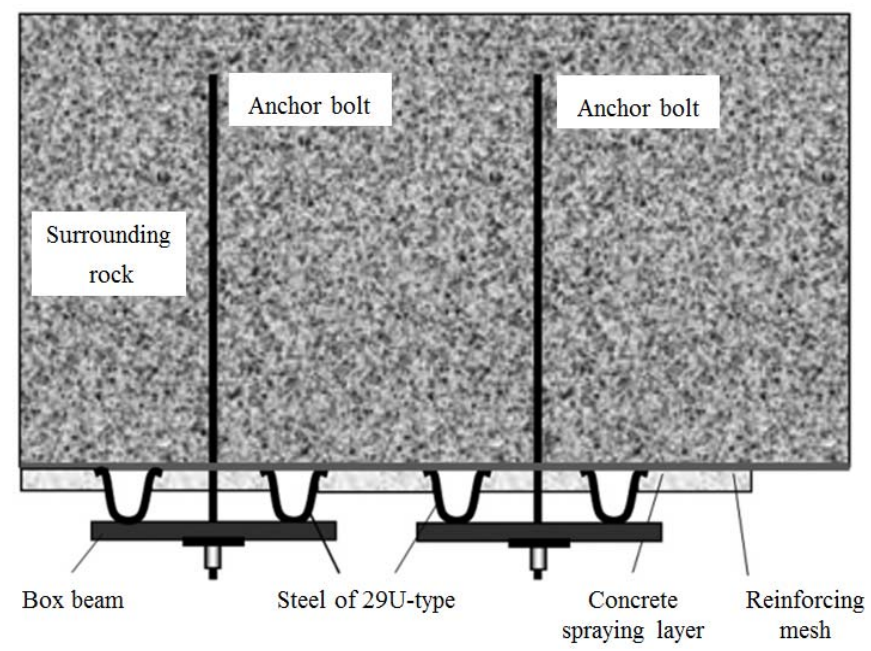

Fig. 1 The combination structure of U-shaped scaffolding, short beam, bolt and concrete spray layer

\subsection{The principle of "the stronger support, the weaker pressure; the weaker support, the stronger pressure"}

When the support strength was stronger, the scope of loose circle was smaller and support pressure bear from the surrounding rock was lower. Conversely, when the support strength was weaker, the scope of loose circle was bigger and support pressure bear from the surrounding rock was larger.

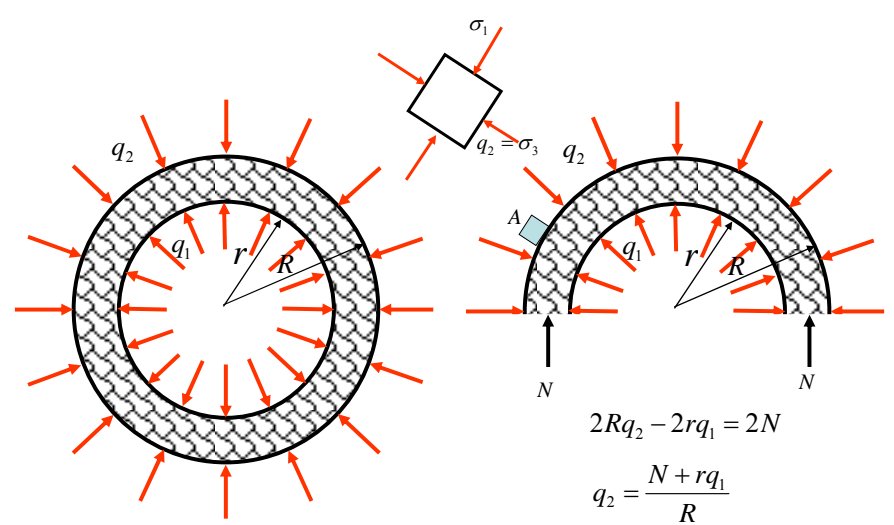

Fig. 2 Schematic diagram of the relationship between the strength of the support and the external pressure of the loose circle

It could be seen from Figure 2 (b), the pressure of $\mathrm{q}_{2}=\sigma_{3}$ acting on the external of the loose circle had a linear relationship with the pressure of q1between supporting structure and rocks, which increased with q1. According to the Coulomb- Navier criteria of " $\sigma_{1}\left[\left(\mathrm{f}^{2}+1\right)^{1 / 2}-\mathrm{f}\right]-\sigma_{3}\left[\left(\mathrm{f}^{2}+1\right)^{1 / 2}+\mathrm{f}\right]=2 \mathrm{C}$ ", the greater the $\sigma_{3}$, the more close to $\sigma_{1}$, the more stable periphery rock mass. Otherwise, the loose circle would continue to expand. And the expansion of loose circle would lead to the increase of $\sigma_{1}$. At this time, in order to suppress the loose circle continues to expand, the value of $\mathrm{q}_{2}=\sigma_{3}$ must improve according to the Coulomb- Navier criteria. According to the relationship of figure (b), it can be known that in the case of keeping the $\mathrm{N}$ constant, the balance state of the loose circle can be kept only by increasing the $\mathrm{q} 1$.

\section{IN-SITE INDUSTRIAL TEST}

\subsection{Project overview}

The occurrence of coal seams in Guobei Coal is stable, but the structure is complicated, and the mechanical characteristics are very special. Complex structure mainly manifested as containing many dirt band in coal seam. Mechanical characteristics of very special mainly manifested as extremely low strength of coal, which could broke with a little touch and belongs to category of extremely loose coal seam. On account of extremely loose and weak coal seam, the lateral pressure coefficient of coal is larger. Manifesting in aspect of roadway support, lateral pressure is very big, column leg is seriously inside moving and support is very difficult.

In 8203 roadway, the roadway section was $4628 \times 3600 \mathrm{~mm}$. The supporting form used $36 \mathrm{U}$ type steel bracket of circular arch with inclined legs and 36U type steel bracket of circular arch with arched legs respectively between December 2008 and March 2009. However, due to the extremely loose of coal seam, the floor was very weak and the support was difficult to maintain more than 10 days. The whole construction process was in the condition of digging before and repairing after. The footage of 2 month was less than $100 \mathrm{~m}$ and the construction organization changed several.

\subsection{Geological and hydrological conditions}

The distance from upper limit of the surface to bottom mudstone of the third aquifuge and bottom margin of the fourth aquifer was about $200 \mathrm{~m}$. Therefore, the new layer aquifer had no direct effect on the surface mining. The main water sources which had influence on this surface were sandstone fissure water of Group 8 coal top and bottom floor. The upper roof in this section of Group 8 coal were siltstonefine sandstone with thickness of $21.12 \sim 25.72 \mathrm{~m}$. The fracture was relatively developed, and had a relatively strong watery. The phenomena of roof raining and water spraying in a short time might be oc- 
curred during the process of construction. The distance from "Taiyuan limestone" to Coal 8 floor was ranged $108 \mathrm{~m}$ to $134.5 \mathrm{~m}$ within the working range. The average distance was $121 \mathrm{~m}$. Normally, Taiyuan limestone water had no effect on production.

\subsection{Geological characteristics of project}

The corresponding dip angle (degree) of 8203 working face of coal seam was $19^{\circ} \sim 31^{\circ}$. And the average value was $26^{\circ}$ with stable occurrence and more complex structure. Coal 81 was ranged from darkgray to black, powder to fragment. It belonged to semi-dark type coal and contained thin layer dirt band partly with thickness of $0.20 \mathrm{~m}$. The thickness of Coal 81 was $4.28 \sim 6.84 \mathrm{~m}$, average of $5.55 \mathrm{~m}$. Coal 82 was ranged from black powder-like to fragment, scaly locally. It belonged to semi-dark type coal. It contained a thick layer of $0.20 \mathrm{~m}$ dirt band in the part to bottom. The thickness of Coal 82 was $2.46 \sim 3.84 \mathrm{~m}$ (an average of $3.23 \mathrm{~m}$ ). The dirt band between Coal 81 and Coal 82 was bulk mudstone of grey to dark-grey, siltstone in partly, brittle, and contained plant fossil. The thickness was $0.78 \sim 5.49 \mathrm{~m}$ (an average of $2.30 \mathrm{~m}$ ). It had trend of outer section thick, internal section thin overall. And the outer section had tendency of thick in upper section and thin in bottom. The total thickness of coal (rock) layer was $8.78 \mathrm{~m}$. The bottom floor was soft- weak mudstone. The original design of 8203 working face was $1200 \mathrm{~m}$ of moving length, $148 \mathrm{~m}$ of tendency length, an area of $173900 \mathrm{~m} 2,2.1375$ million tons of geological reserves and about 1.92 million of recoverable reserves.

\subsection{Geological characteristics of project}

Support parameters: the metal support are $600 \mathrm{~mm}$ of row spacing and 36U-type steel in the above two schemes.

\subsubsection{Main supporting technology parameters}

(1) Component parameters of main body support

(1) Bracket: Metal bracket uses three sections of U36-type steel. The radius of semicircular arch is $2.3 \mathrm{~m}$. The width of roadway floor is $4993 \mathrm{~mm}$ and the high is $3600 \mathrm{~mm}$. The basal area is $14.58 \mathrm{~m}^{2}$. The shed distance is $500 \mathrm{~mm}$. The top beam is a circular arc shape with arc length of $5236 \mathrm{~mm}$ and shed leg length of $3265 \mathrm{~mm}$. The lap length of leg beam is $500 \mathrm{~mm}$ and overlapping part connects with three snap rings.

(2)Bolt: Bolt uses non-longitudinal rib screw thread steel of high strength pre-stressed bolt of $\Phi 22 \mathrm{~mm} \times 2400 \mathrm{~mm} 20 \mathrm{MnSi}$. Bolt tray is cold rolled steel of plate type tray of $10 \times 150 \times 150 \mathrm{~mm}$. The arrangement of bolt is shown in figure 5 .

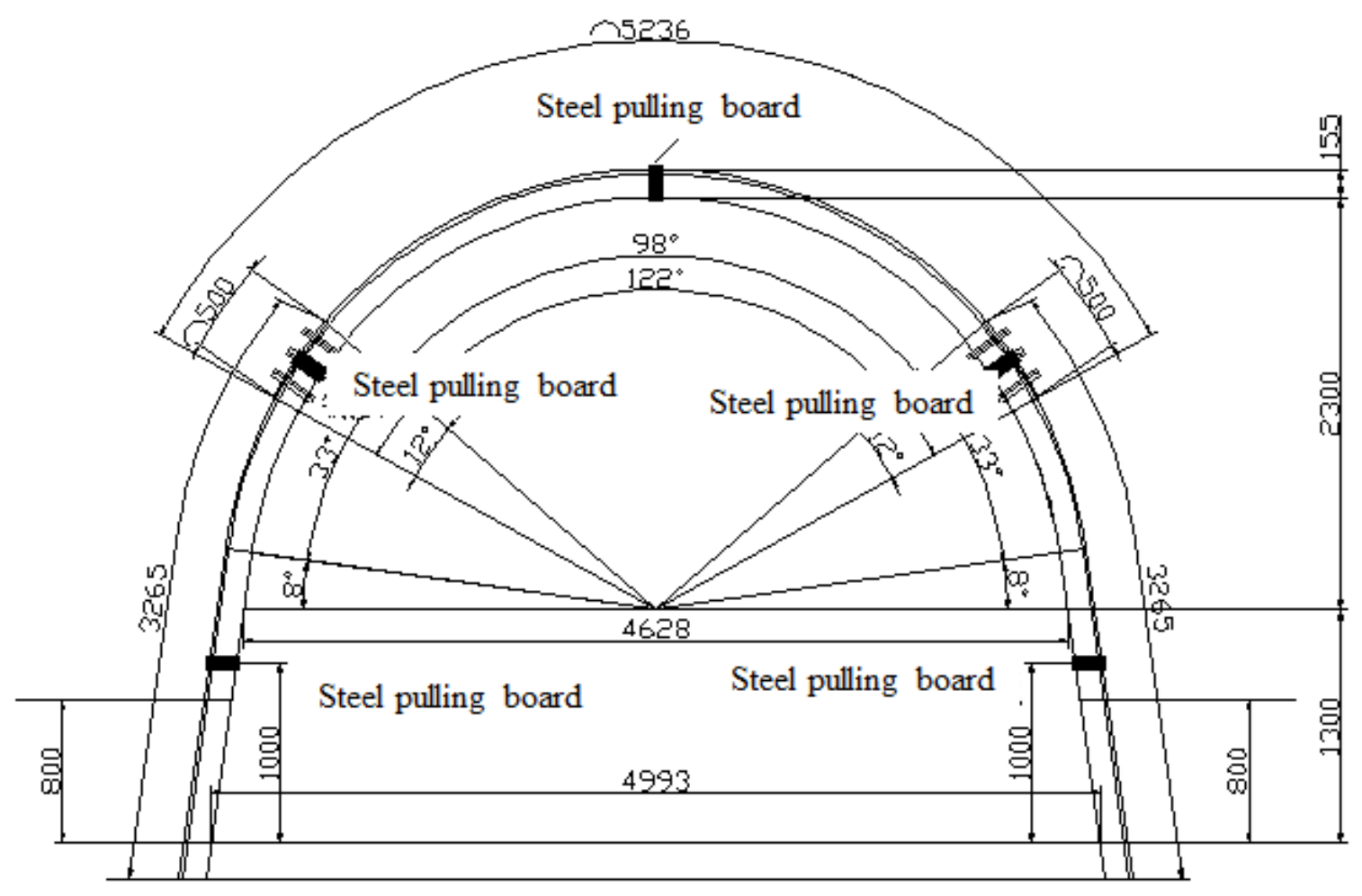

Fig. 3 The initial supporting scheme 


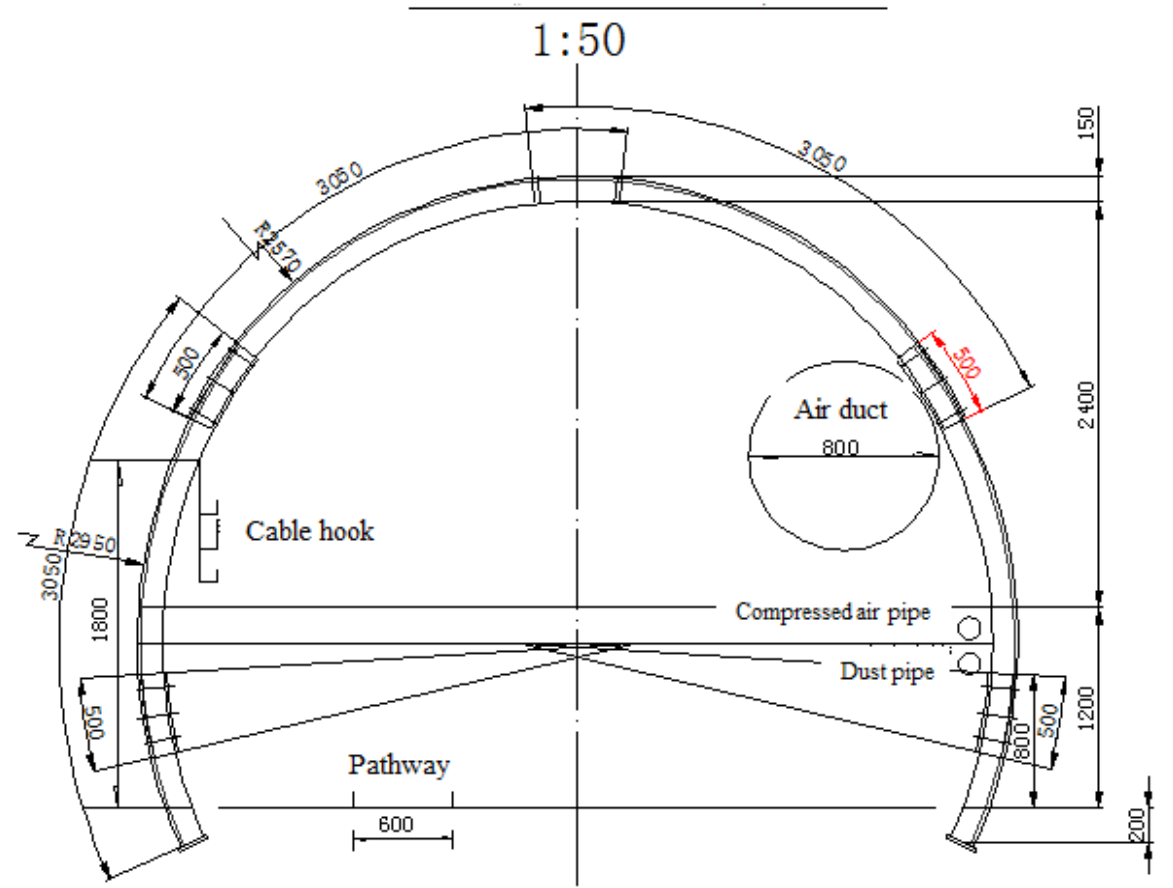

Fig. 4 Modified supporting scheme

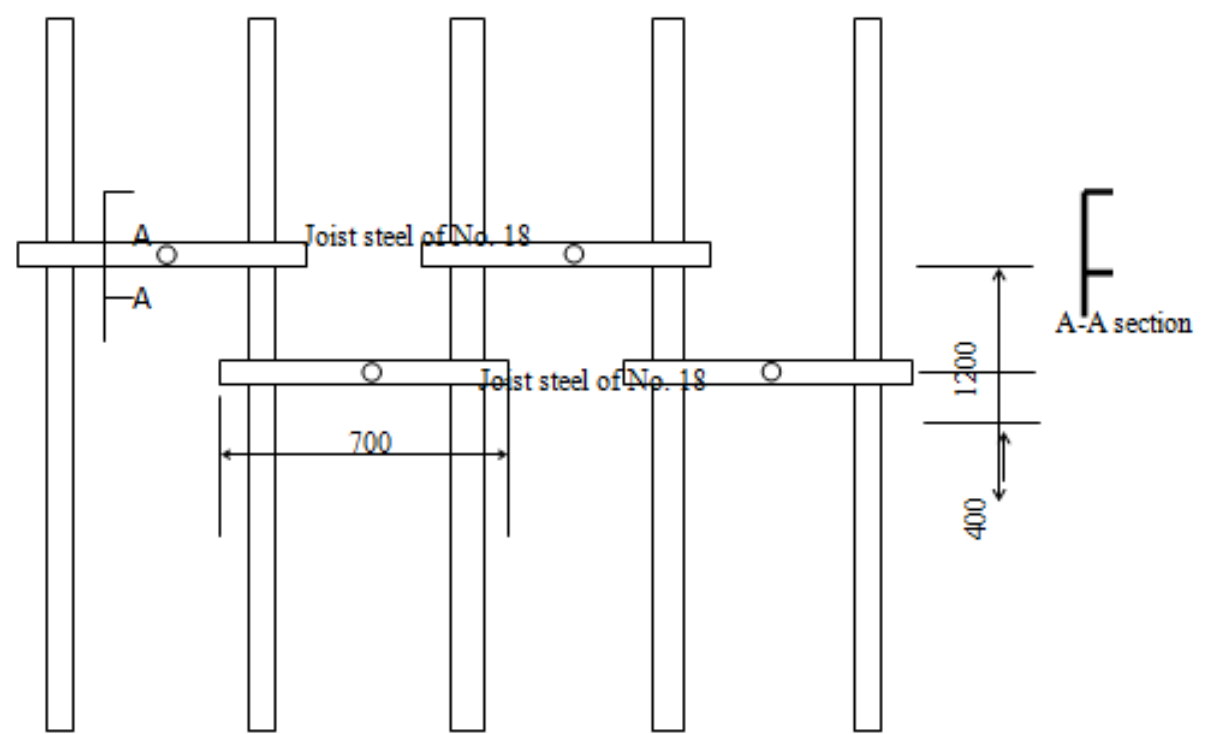

Fig. 5 Arrangement plan of roadway bolt in 8203 mining area

Table 1 the related supporting parameters

\begin{tabular}{|c|c|c|c|c|c|c|c|c|}
\hline Tunnel name & Section shape & $\begin{array}{c}\text { Surrounding } \\
\text { rock type }\end{array}$ & $\begin{array}{c}\text { Type of coal } \\
\text { seam }\end{array}$ & Net height & Net width & Shed distance & $\begin{array}{c}\text { Shed beam } \\
\text { segment num- } \\
\text { ber }\end{array}$ & $\begin{array}{c}\text { Lap } \\
\text { length }\end{array}$ \\
\hline $\begin{array}{c}8203 \text { machinery } \\
\text { roadway }\end{array}$ & Skew arch & $\mathrm{F}>3$ & 81,82 & 3600 & 4993 & 500 & 3 & 500 \\
\hline \multicolumn{7}{|c|}{ Bracket } \\
\hline Cable spacing & $\begin{array}{c}\text { Nut tightening } \\
\text { torque }\end{array}$ & $\begin{array}{c}\text { Depth of ham- } \\
\text { string }\end{array}$ & material & Specifications & material & Specifications & spacing & $\begin{array}{c}\text { Net lap } \\
\text { length }\end{array}$ \\
\hline 230 & $\geq 300$ n.m & 200 & $\begin{array}{c}36 \text { USection } \\
\text { steel }\end{array}$ & $180 \times 150$ & $\begin{array}{c}\text { Steel bar } \\
\text { net }\end{array}$ & $700 \times 1300$ & Fully closed & $100 \mathrm{~mm}$ \\
\hline
\end{tabular}

Description: 1 table in the parameters of the unit for the $\mathrm{mm}$, bracket and its components, parts of the material, the quality must meet the requirements of the design and the relevant standards 2 leg tie angle $8^{\circ}$. 


\section{ROADWAY MONITORING OF INDUSTRIAL TEST}

\subsection{Layout of observation station}

Mine pressure observation stations of totally eight were arranged in Roadway 8203 of Guobei Mine. The station spacing was $5 \mathrm{~m}$. The distance from observation station 8 to the head-on was $9 \mathrm{~m}$, as shown in Figure 6. Every observation station contained four observation points: roof observation point, the bot- tom floor observation point and two side's observation point, as shown in Figure 7.

In these eight observation stations, the layout method of two sides and roof observation point were: the steel bar of diameter $10 \mathrm{~mm}$ was bent to hook and welded in the nut which fixed on the Ushaped shed to act as observation point. The layout method of floor observation point were: the steel bar of diameter $10 \mathrm{~mm}$ was bent to hook and welded in the crooked chisel of $10 \mathrm{~mm}$ in diameter and $300 \mathrm{~mm}$ in length, smashing into the floor to act as observation point.

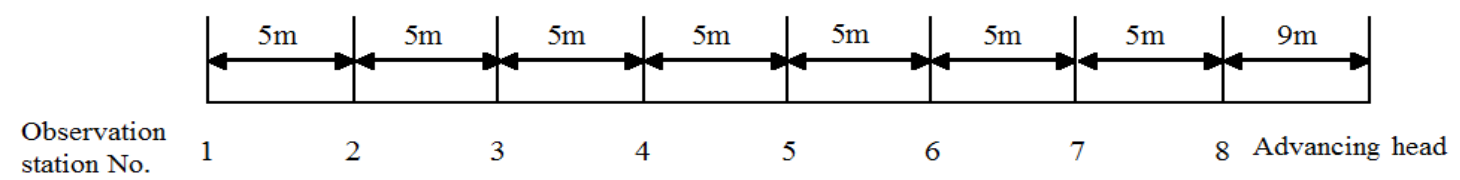

Fig. 6 Schematic diagram of instrument station layout (unit: m)
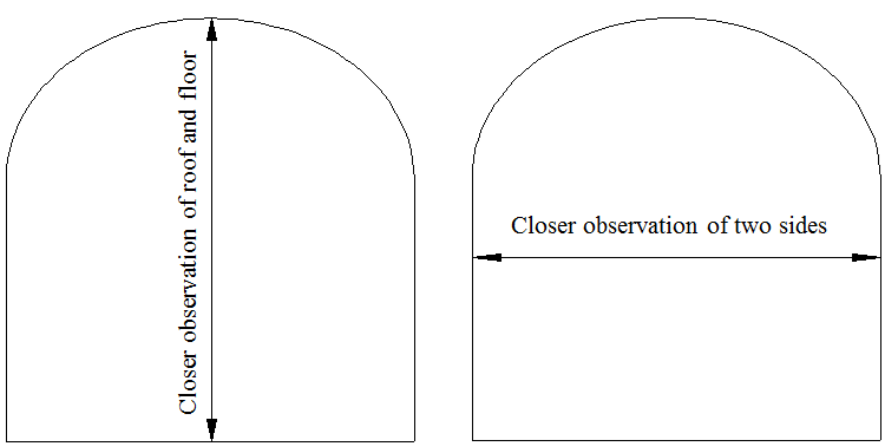

Fig. 7 Schematic diagram of measured point positon in instrument station

\subsection{Methods of observation}

Roadway deformation test was divided into 5 stages, the first stage was the test of dynamic pressure impact stage, and the rest is the effect monitoring stage.

After arranged the observation points, it observed once a day for five days of continuous observation. The purpose was to understand the influence of dynamic pressure on roadway deformation. After five days, the roadway excavation excelled more than $30 \mathrm{~m}$ and the roadway deformation was in stable stage. And then tested the well once every three days and filled in the test records at the end of test. The difference between the test results and the previous test results was the deformation value of roadway during the two tests. The difference between the test results and the test results of first time was the total deformation value of roadway throughout the total tests.
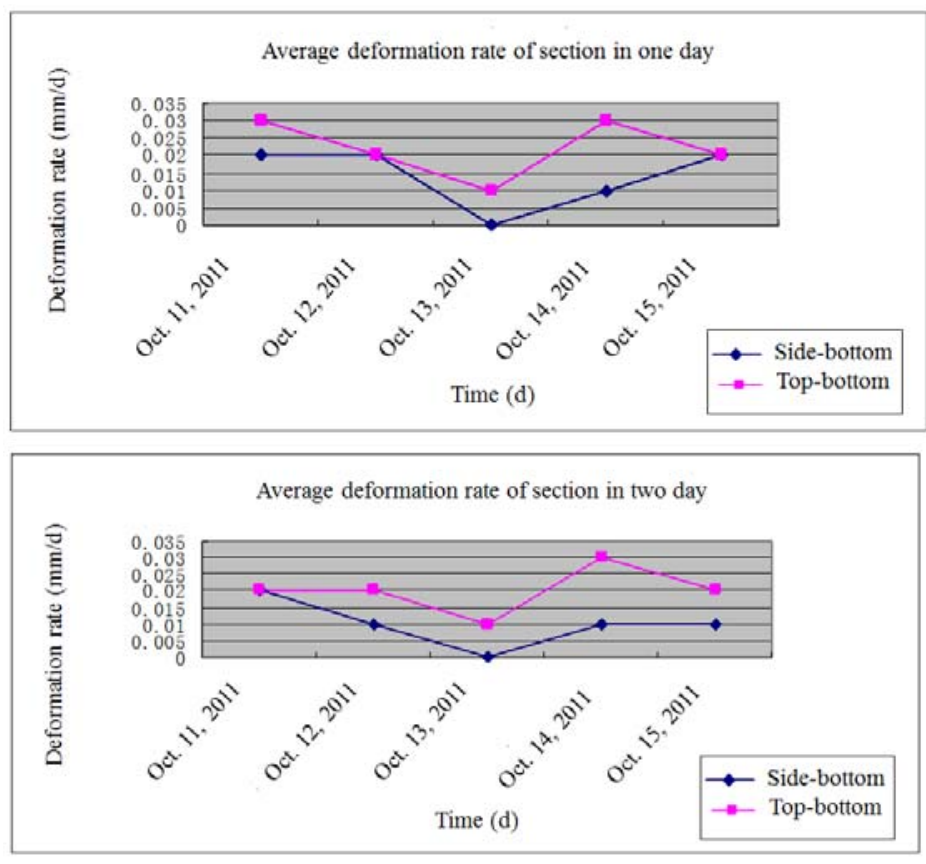

Fig. 8 Deformation rate of top-bottom and side-bottom in one day and two day

Dynamic pressure test lasted for 7 days in order to grasp the relationship between the dynamic pressure caused by the roadway deformation and the advance of the excavation working face. The second deformation stage observed 36 days. The main test content included the convergence of the roadway roof, the sides' bottom of U-shaped shed, the shed legs U-shaped shed and the convergence rate of the top and floor of the roadway. In the observation of third deformation stage, two sections were selected for monitoring effect and monitored continuously for 7 days. There were two kinds of monitoring content: the closer moving distance of side's bottom, the closer moving distance of roof and floor. In the observation of fourth deformation stage, two sections were selected for monitoring and monitored continuously for 6 days. There were two kinds of monitor- 
ing content: the closer moving distance of side's bottom, the closer moving distance of roof and floor. In the observation of fifth deformation stage, two sections were selected for this monitoring effect and monitored continuously for 5 days. The monitoring content was the closer moving distance of side's bottom.

After nearly mining in the working face and through the five stages of monitoring data and onsite observation, the roadway was still intact. It realized zero rework record of 4 years for the first time in roadway of extremely loose and extra thick coal seam in domestic.

\section{CONCLUSIONS}

1) The principle of "the stronger support, the weaker pressure; the weaker support, the stronger pressure" and related key technologies better revealed the applicability in deep-thick extremely loose coal seam from the aspect of mechanical mechanism. Good application effect also fully demonstrated its relatively broad promotional value in roadway support of deep-thick extremely loose coal seam.

2) Aiming at pressure distribution characteristic of overall along goaf roadway, the reinforcing supporting scheme of anchor frame put forward. The monitoring results showed that the implementation of the scheme could be well controlled surrounding rock deformation and meet the requirements of safe production. It has great economic benefit and social benefit.

\section{REFERENCES}

Bai Jianbiao, Wang Xiangyu, Jia Mingkui, et al. Theory and application of supporting in deep soft roadways [J]. Chinese Journal of Geotechnical Engineering, 2008, 30(5):632-634.

Chen Baoyuan. Application of truss bolt supporting technology in roadway with secondary dynamic pressure behavior $[\mathrm{J}]$. Coal Mining Technology, 2010, 15(4): 76-78.

He Changhai, Jiang Yaodong, Zeng Xiantao, et al. Numerical simulation for supporting optimization of anchored bolt with high strength and high pre-tightening in deep mine $[\mathrm{J}]$. Coal Mining Technology, 2010, 15(3):50-53.

Jiang Yaodong, Liu Wengang, Zhao Yixin, et al. Study on surrounding rock stability of deep mining in Kailuan mining group [J]. Chinese Journal of Rock Mechanics and Engineering, 2005, 24(6):1857-1862.

Jing Laiwang, Jiang Qing, Liu Ning. Numerical simulation and analysis of U-shape steel support in extremely-soft coal roadway [J]. Coal Mining Technology, 2012, 17(6):48-51.

Li Jianmin, Zhang Zhiyan. Homogeneous supporting technology of cracked roadway surrounded by soft rock and its application in deep mine [J]. Coal Mining Technology, 2011, 16 (1): 60-63.

Liu Chaoru. Qualitative analysis of influence of surrounding rock creep deformation on supporting stress field in deep roadway [J]. Coal Mining Technology, 2011, 16 (6): 51-54.
Sun Xiaoming, He Manchao. Numerical simulation research on coupling support theory of roadway within soft rock at depth [J]. Journal of China University of Mining \& Technology, 2005, 34(2):166-169.

Wang Hezhi, Wang Cheng, Han Changliang, et al. Integrated control technology of the roadway in the loose coal seam below close range goaf [J]. Science \& Technology Information, 2008, (25):58-60.

Wan Shiwen, Li Feng, Wang Xiaolin. Application of fulllength pre-stress anchored bolt in roadway with strong dynamic pressure [J]. Coal Mining Technology, 2011, 16 (1): 32-34.

Wu Pengfei. Research on roadway supporting technology in the tectonic structure zone [D]. Taiyuan: Taiyuan University of technology, 2010.

Zhang Nong, Wang Cheng, Gao Mingshi, et al. Roadway support difficulty classification and controlling techniques for Huainan deep coal mining [J]. Chinese Journal of Rock Mechanics and Engineering, 2009, 28(12):2421-2428.

Zhao Hongchao, Chen Yong. Technology of surrounding rock control by whole-pouring in roadway retained along gob [J]. Coal Mining Technology, 2011, 16(3): 95-98.

Zhao Yiming, Zhang Nong, Kan Jiaguang, et al. Super-high prestress combination bolts for deep mine coal roadway support [J]. Journal of xi'an university of science and technology, 2008, 28(2):222-225.

Zou Lei, Lai Xingping, Wang Ningbo, et al. Roadway deformation characteristics of steep-thick coal seam under complicated geological conditions [J]. Journal of xi'an university of science and technology, 2010, 30(2):145-149. 